\title{
APPLYING GREY RELATIONAL ANALYSIS TO ITALIAN FOOTBALL CLUBS: A MEASUREMENT OF THE FINANCIAL PERFORMANCE OF SERIE A TEAMS
}

\author{
Sean PRADHAN* \\ Adem BOYUKASLAN** \\ Fatih ECER ${ }^{* * *}$
}

\begin{abstract}
Extant literature on the financial analysis of football clubs has applied a vast array of techniques in determining the fiscal stability of such entities. Although many studies have provided useful comparisons and analyses of the states of various clubs, direct research comparing the financial performance among various clubs is still scant. Hence, we present an application of financial ratio analysis to the greater Italian football market within the Serie A. The main purpose of this study is to assess the financial performance of the top three Italian football clubs currently listed on the Borsa Italiana (Italian Stock Exchange), those being: Juventus F.C., A.S. Roma, and S.S. Lazio. In accomplishing this, we offer a comparative analysis of these clubs through the usage of grey relational analysis (GRA), an optimal performance technique derived from engineering. Overall, our results suggest that S.S. Lazio appears to be the most financially stable club among the sampled, publicly traded Serie A teams. In light of these findings, this study furthers the application of economic evaluation into larger segments of international football.

Among several models, 18-20-1 structured MLP has best explanatory level with $0.893 \mathrm{R}^{2}$ and 0.207 MSE values. This was followed the 18-16-1 structured MLP which had the minimum MSE as 0.025 and $0.88 \mathrm{R}^{2}$. These are models 1 and 2 respectively. It is also observed that ECE (Economic Calendar Events) and 'Other' variables have notable effects that explain on the fluctuation of the index. Similarly, the two variables have shown their significant in other models as well. Prediction of opening is more successful than closing. ECE has greater success forecasting open prices.
\end{abstract}

Key words: Serie A, Italian football clubs, financial ratios, financial performance, grey relational analysis.

Jel Codes: C44, C58, G00, L25, L83, P51

\footnotetext{
* Doctoral Student, Univestiy of Michigan, seanprad@umich.edu.

** RA., Afyon Kocatepe University, ademboyukaslan@aku.edu.tr.

*** Assoc. Prof., Afyon Kocatepe University, fecer@aku.edu.tr.

Date of submission: 07.02.2017

Date of acceptance: 19.04.2017
} 


\section{INTRODUCTION}

Football is the most played, watched, and followed sport in the world. With over 3.5 billion fans (Pattnaik and Bag, 2015), nearly half of the entire world's population, football is iconic around the globe. With Europe as its epicenter, the sport has experienced a steady market growth across the “Big Five” European soccer leagues (i.e., Bundesliga, La Liga, Ligue 1, Premier League, and Serie A). Just last year, the leagues were able to collectively generate $€ 13.6$ billion in revenue, an increase from $€ 12.1$ billion in the previous year (Deloitte, 2016). Teams along the European continent have basked in the success of this growth, experiencing escalations in their overall worth. Within recent years, scholars in both economics and sports analytics have attempted to measure this growth and quantify differences between interleague clubs.

From both an on-field and economic perspective, clubs that thrive in one area tend to do well within the other. For instance, some of the most successful and most valuable clubs in the world, such as Real Madrid, Barcelona, and Manchester United, report very high revenue figures whilst realizing collective triumph within their respective leagues. Nevertheless, financial performance is not solely dependent on revenue and overall club worth. For instance, clubs, such as Deportivo de la Coruña, Marseille, Glasgow Rangers, Borussia Dortmund, as well as Valencia, have had difficulty translating success on the pitch toward monetary attainment. Within this list of exemplary clubs, Deportivo, in particular, has experienced some of the greatest adversities in this respect. Over the years, Deportivo has undergone a series of upheavals from functional prominence with an appearance in the Champions League semifinals in 2004 to relegation and near insolvency during the early 2010s. Their financial adversities persist, as the club has most recently filed for bankruptcy security along with fellow La Liga affiliate, Valencia (Franck, 2014).

Taking this example into consideration, economic success within football is determined by a holistic view of financial records, involving a series of assessments accounting for revenue along with debt, assets, working capital, and effectual management of other liabilities. In other words, financial analyses of football clubs must be considered from a wider perspective and must examine simply how performance as well as club management translates to financial success. In view of such financial success and on-field performance, Italy may provide a noteworthy façade for such financial analyses. While some of the most valued clubs in the world have predominantly originated from England and Spain, Italian clubs of the Serie A have steadily surfaced at the top of this list. For instance, Forbes (2016) has valued Juventus F.C. (\$1.299 billion) and A.C. Milan (\$825 million) as the respective ninth and eleventh most valuable clubs in the world. At present, Inter Milan (\$559 million; i.e., sixteenth most valuable) and Napoli (\$396 million; i.e., nineteenth most valuable) have also joined 
their Serie A competitors in the top 20 (Forbes, 2016). While fluctuations in revenue and debt have led to diminishments in the overall value, clubs such as A.S. Roma as well as S.S. Lazio have frequently appeared on these top valued lists over the past decade.

Interestingly, however, A.S. Roma, S.S. Lazio, and Juventus F.C. are currently the only three clubs that publicly offer shares on the Italian Stock Exchange, the Borsa Italiana. Lazio first released its initial public offering (IPO) in 1998, followed by Roma in 2000, and Juventus in 2001 (Günnemann, 2005). Over their time on the Borsa Italiana, each club has reasonably increased their share values due to both effective club management in addition to strong performance within the Serie A. Among the three floating clubs, Juventus has been far and away the most successful team. With a total of 32 Scudettos (league titles), 11 Coppas Italia (Italy Cups), 7 Supercoppas Italiana (Italian Super Cups), and 2 Union of European Football Associations (UEFA) Champions League trophies (Juventus Football Club S.p.A., 2016), their accomplishments as an Italian club are unprecedented. During the past five seasons, the club has continued to thrive on the pitch, most recently capturing their fifth consecutive Serie A title, 2 Italy Cups, 3 Italian Super Cups, and finishing as runner-up in the UEFA Champions League final in 2015 and qualifying to the round of 16 in 2016.

Contrarily, Roma and Lazio have not had near the on-field success resembling Juventus. With a mere 5 Serie A league titles and 5 Italian Super Cups between them, their on-field performances have been feeble in comparison (A.S. Roma, 2016; S.S. Lazio, 2016). However, in this time, Roma has seen an upsurge in performance, having had a span of some of their finest seasons in their existence, finishing in the top three in the Serie A from the 2013/14, in which they qualified for the Italy Cup, to the 2015/16 seasons. In contrast, with the exceptions of the 2012/13 season where Lazio won the Italy Cup and the 2014/15 where they finished third in the Serie A, Lazio’s performance over the past five years has been subpar, as the club has not been a top contender within league play or international competition. Nevertheless, Lazio has been able to maintain their place within the top 10 of the Serie A over the past five years. Thus, the incongruence in performance on the pitch between these clubs has been favorably dominated by Juventus, as also displayed in Figure 1. Although these teams may each be in different classes with regards to sporting success, an examination of their economic statuses could potentially reveal variations in the present context. 
Fig 1. Sporting success of publicly traded Serie A Clubs

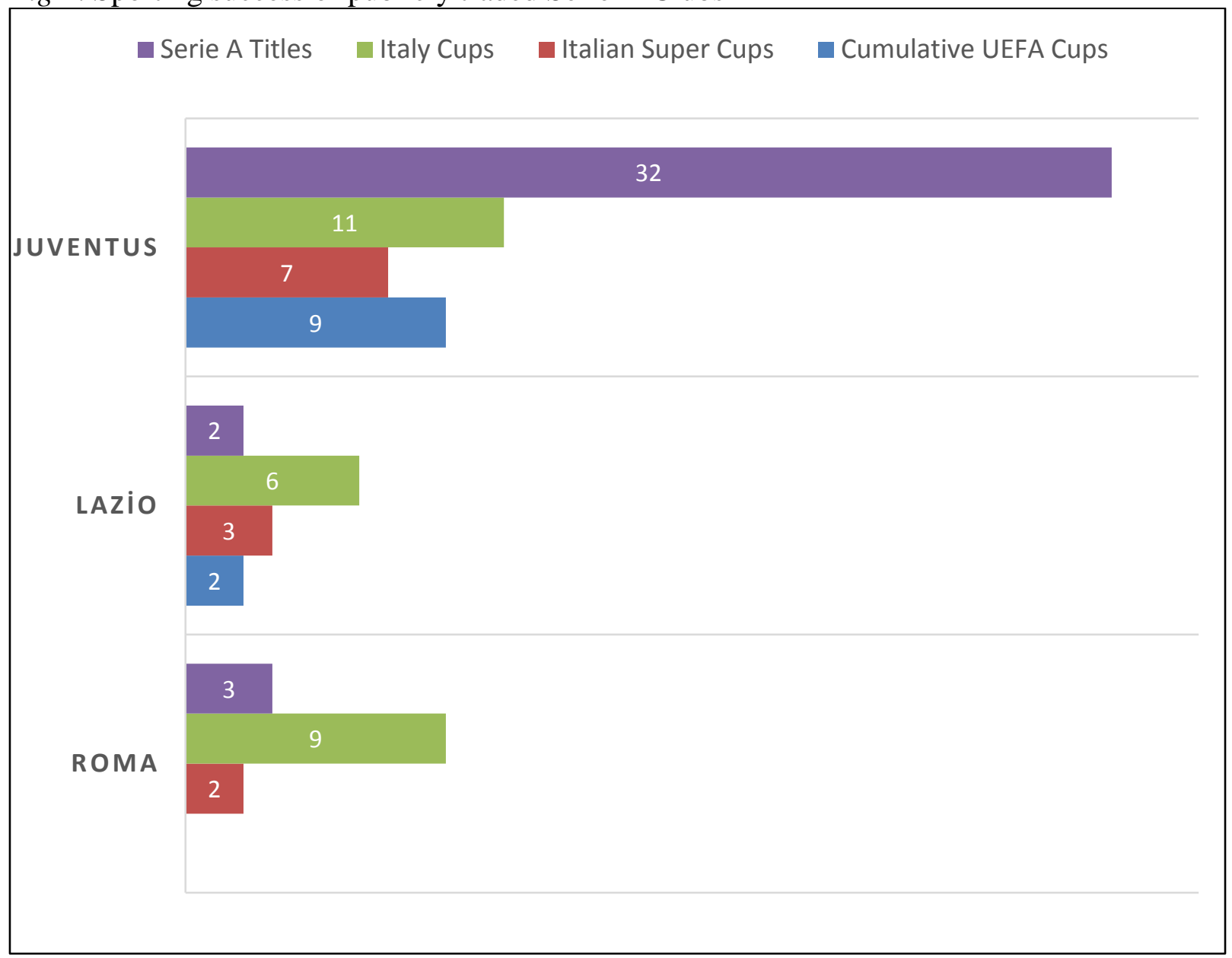

(Sources: A.S. Roma [2016], Juventus Football Club S.p.A. [2016], S.S. Lazio [2016]).

\section{LITERATURE REVIEW}

Prior work on financial analysis in football has often evaluated the economic performances of various clubs. Predominantly, previous research has centered upon applying various techniques to compare the financial effectiveness of such teams. Within the greater European front, many studies have focused on English Premier League (EPL) teams. With numerous examinations on the financial profitability of the EPL itself (Hamil and Walters, 2010), game-related performance evaluations on financial efficiency of publicly traded clubs (Zuber, Yiu, Lamb, and Gandar, 2005), as well as linear analyses on productivity (Guzman and Morrow, 2007), case-by-case analyses have been lacking. Recently, Gunardi (2014) conducted a financial case analysis of Manchester United, examining ratios in determining financial performance. Keeping the UEFA's Financial Fair Play (FFP) initiative in mind, Gunardi (2014) reported that Manchester United although solvable, struggled with respect to profitability given the high presence of debt. While Manchester United may have reported high revenue figures, their overall present state was erratic even though performance on the pitch was 
robust. Consequently, these results truly reflect the discrepancy between on-field performance and overall financial performance.

Further within the financial analyses of football, existing literature has examined some cases from Italian football. For instance, Baroncelli and Caruso (2011) analyzed the fundamentals of top Italian football clubs and related economic aspects. They also provided an overall evaluation of the financial situation in Italian football, noting that these clubs have not been able to maximize commercial success through worldwide broadcasting. Boeri and Severgnini (2014) have indicated that the financial conditions of Italian football are extremely punitive given the high mortality rate amongst clubs. According to the authors, among 37 teams participating in the Serie A from the 2001/02 to 2010/11 seasons, approximately 25 percent of these clubs have had to declare bankruptcy. Considering this, the balance between debt and profit and/or losses of teams are of great concern on the Italian front. Building upon this, Barros and Rossi (2014) have proposed a Bayesian stochastic frontier model to analyze the technical efficiency of Serie A Italian football clubs. The findings from their study also show that efficiency varies drastically among clubs.

Furthermore, there also exist a number of studies of financial performance in other contexts of European football. Berument et al. (2006) have demonstrated the effects of foreign wins among Turkish clubs. They report that for some clubs, specifically Beşiktaş, match success in the Winner's Cup against international clubs can translate to share returns. However, Demir and Danis (2011) have shown how the stock prices of various Turkish clubs may have an asymmetric association between financial returns and on-field performance. Dependent on the public presentation, the club’s stock prices were significantly affected by domestic cup wins in comparison to European cup wins. In relation to the vast research of Turkish clubs as well as hierarchal methods of club analysis, Ecer and Boyukaslan (2014) have offered a useful financial evaluation of the performances of the top four clubs in Turkey whose shares are being traded on the Istanbul Stock Exchange, Borsa Istanbul. Using a series of financial ratios as well as grey relational analysis (GRA), they were able to reveal the financial states of Galatasaray, Beşiktaş, Fenerbahçe, and Trabzonspor. Overall, their analyses indicated that Fenerbahçe was the most financially successful club among the four floating Turkish teams. In sustenance, Sakinç (2014) conducted follow-up analyses employing a modified set of financial ratios to compare these four clubs. Using similar GRA methods, Sakinç (2014) was able to sustain Fenerbahçe's place as the top ranked financially stable club and provide support for findings by Ecer and Boyukaslan (2014).

Among the hierarchal pieces of financial analysis, many methods can be employed to measure various clubs among competitors. Using Multi-Criteria Decision-Making (MCDM) techniques (e.g., Data Envelopment Analysis [DEA] and Technique for Order of Preference by Similarity to Ideal 
Solution [TOPSIS]), Kiani Mavi et al. (2012) studied the efficiency of German Bundesliga clubs, evaluating the performances of such teams using financial accounts from the 1999/2000 season. Within the EPL, Barros et al. (2006) utilized an econometric frontier model to determine how various factors could influence financial efficiency. Overall, they delivered a comprehensive ranking of the top EPL clubs, finding clusters of clubs characterized by elite, middle, or low financial performance. Within Italian football, ordinal analyses have characterized Serie A teams according to performance on the pitch. Montanari et al. (2008) examined how the stability and tenure of team members could affect performance. Not surprisingly, they report that these variables can have a positive impact on team performance.

However, from a financial standpoint, Serie A clubs have been the target of discrepant evaluation due to volatility within the Italian market. As shown by Baroncelli and Lago (2008), during the early 2000s financial crises, Italian clubs suffered from a revenue standpoint. Given the presence of some teams floating shares on the stock exchange, Boidoa and Fasanob (2007) have elucidated some precarious cases within the Serie A. Likewise, these authors provide evidence for sports performance-based influences on financial performance of the Serie A clubs. However, in terms of hierarchical procedures among the Italian teams, there exists a gap in this sector of football. Considering this, the Serie A clubs may present a promising avenue for analysis to be conducted.

Thus, in this study we aim to evaluate the performances of Italian football clubs through an examination of financial statements from the past five most recent seasons of play in the Serie A (i.e., the 2011/12-2015/16 seasons). In extension of the work by Ecer and Boyukaslan (2014), this paper will utilize a series of financial ratios as the primary data to rank the financial performance of the sampled clubs. In doing so, we intend to conduct a grey relational analysis (GRA) to systematically rank the three Serie A clubs floating on the Borsa Italiana, the Italian stock exchange market (i.e., Juventus F.C., A.S. Roma, and S.S. Lazio). The remainder of this study is organized as follows: in Section 3, a description and computation of financial indicators of performance is offered. The GRA method is introduced in Section 4. Subsequently, the results of the GRA analysis are reported in Section 5. A discussion of our findings is presented in Section 6. Finally, future directions for research and conclusions are offered in the final segment of this study, Section 7.

\section{FINANCIAL INDICATORS OF PERFORMANCE}

In determining each club’s current financial performance, we provide a calculation of a series of financial ratios, as also employed by Ecer and Boyukaslan (2014; see Table 1). In doing so, we seek to examine each club's performance through an assessment of indicators of liquidity, liability, and profitability. Measures of liquidity are represented by the current (CR) and liquid asset 
ratio (LAR). Liability is signified by net working capital/total assets (NWC/TA), total liabilities/total assets (TL/TA), total liabilities/equity (TL/E), short-term liability/equity (STL/E), fixed assets/equity (FA/E), and tangible assets/total assets ratios (TA/TA). Short-term liabilities are defined as current liabilities due in the present year. Fixed assets involve entities to be held in the long term, such as property and equipment. Tangible assets deal with both fixed and current assets (i.e., inventory, cash, and cash equivalents). Finally, profitability is denoted by earnings per share (EPS), net capital/equity (NC/E), and net profit/total assets (NP/TA). Ecer and Boyukaslan (2014) propose that the higher each liquidity and the lower each liability ratio, the more likely a club is able to manage liabilities with their capital, minimize financial risk, and ultimately provide higher profit margins for investors. Therefore, the goal for businesses is to reach higher ratios of liquidity and profitability to reflect financial potency. Contrariwise, clubs with higher liability ratios pose greater risk for prospective investors. As a result, the aim for these ratios are lower values of liability.

Table 1. Financial ratio formulas

\begin{tabular}{|c|c|c|c|}
\hline Financial Indicator & Ratio & $\begin{array}{c}\text { Formula } \\
\text { Current Assets (CA) }\end{array}$ & $\begin{array}{l}\text { Goal } \\
\text { Higher }\end{array}$ \\
\hline \multirow{5}{*}{ Liquidity } & Current Ratio (CR) & Current Liabilities (CL) & \\
\hline & Liquid Asset Ratio (LAR) & $\frac{\text { Liquid Assets (LA) }}{\text { Current Liabilities (CL) }}$ & Higher \\
\hline & Net Working Capita1 NWC T Total Assets (TA) & Current Assets (CA) - Current Liabilities (CL) & Lower \\
\hline & 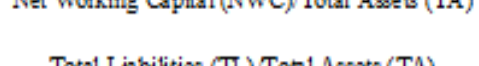 & $\begin{array}{c}\text { Total Assets (TA) } \\
\text { Toa1 Liabilities (TL) }\end{array}$ & Lower \\
\hline & Total Liabilities (TL)/Tota1 Assets (TA) & $\begin{array}{l}\text { Total Assets (TA) } \\
\text { Tota1 Liabilities (TL) }\end{array}$ & Lower \\
\hline \multirow[t]{5}{*}{ Liability } & Iotal Liabilftes (IL) i quaty (E) & $\begin{array}{c}\text { Equity }(\mathrm{E}) \\
\text { Current Liabilities (CL) }\end{array}$ & Lower \\
\hline & Short Term Liability (STL)/Equity (E) & $\begin{array}{c}\text { Equity (E) } \\
\text { Fixed Assets (FA) }\end{array}$ & Lower \\
\hline & Fuxed Assets (FA) Equity (E) & $\begin{array}{c}\text { Equity (E) } \\
\text { Tangible Assets (TA) }\end{array}$ & Lower \\
\hline & Tangible Assets (TA) Total Assets (TA) & Total Assets (TA) & \\
\hline & Net Capital (NC) Bquity (E) & Net Capital (NC) & Higher \\
\hline \multirow[t]{2}{*}{ Profitability } & & $\begin{array}{l}\text { Equity (E) } \\
\text { Net Profit (NP) }\end{array}$ & Higher \\
\hline & Net Profit (NP)/Toal Assets (TA) & Total Assets (TA) & \\
\hline
\end{tabular}

Note. Adapted from Ecer and Boyukaslan (2014).

\section{III.I. Financial Ratio Analysis}

In evaluating each Serie A club, we present financial ratio analyses from the past five seasons using the average respective figures in determining the present states of each club (see Table 2 for financial figures). Our primary set of analyses assess each club’s financial standing with respect to its fellow Serie A competitors. As previously noted, these teams were selected as comparative cases given that they all similarly float on the Italian Stock Exchange. In examining each of the ratios, illustrated in Table 3, we can summarize our findings as follows:

- CR: In comparison to Lazio and Roma, Juventus' CR is quite low, signaling that the club may have some difficulty meeting its current liabilities using current assets. Among the clubs, 
Roma and Lazio appear to respectively have the best abilities to manage debts given the higher CR.

- LAR: Overall, each club has relatively weak cash power. However, Juventus struggles the most in this aspect given its marginal LAR.

- $\quad$ NWC/TA: Within this area, each of the clubs holds negative capital ratios, which may suggest insufficiency in regards to liquidity.

- TL/TA: With respect to total liabilities over total assets, Lazio appears to have the least difficulty in this matter. Roma holds a TL/TA ratio over 1 , signaling a slight struggle to manage liabilities with assets, while Juventus appears to be approaching such difficulties.

Table 2. Financial values for selected Serie A clubs

\begin{tabular}{|c|c|c|c|c|c|c|c|}
\hline Team & Financial Figure & $2011 / 12$ & $2012 / 13$ & $2013 / 14$ & $2014 / 15$ & $2015 / 16$ & 5-year Average \\
\hline \multirow[t]{10}{*}{ Juventus F.C. } & Net Profit & $(48,654,550)$ & $(15,910,649)$ & $(6,674,430)$ & $2,298,263$ & $4,062,312$ & $(12,975,811)$ \\
\hline & Current Assets & $74,038,541$ & $100,373,367$ & $143,724,605$ & $107,895,678$ & $127,166,806$ & $110,639,799$ \\
\hline & Liquid Assets & 653,650 & $1,777,036$ & $1,586,969$ & $3,126,754$ & $42,810,719$ & $9,991,026$ \\
\hline & Fixed Assets & $165,434,492$ & $159,652,162$ & $157,896,670$ & $161,237,406$ & $160,841,009$ & $161,012,348$ \\
\hline & Tangible Assets & $239,473,033$ & $260,025,529$ & $301,621,275$ & $269,133,084$ & $288,007,815$ & $271,652,147$ \\
\hline & Total Assets & $427,780,347$ & $443,366,100$ & $495,921,231$ & $474,268,339$ & $577,558,246$ & $483,778,853$ \\
\hline & Current Liabilities & $258,593,305$ & $295,551,017$ & $357,376,057$ & $312,813,033$ & $267,057,963$ & $298,278,275$ \\
\hline & Total Liabilities & $363,171,764$ & $394,735,085$ & $453,294,731$ & $429,622,895$ & $524,174,658$ & $432,999,827$ \\
\hline & Equity & $64,608,583$ & $48,631,015$ & $42,626,500$ & $44,645,444$ & $53,383,588$ & $, 779,026$ \\
\hline & Earnings Per Share & $(0.09)$ & $(0.02)$ & $(0.01)$ & 0.00 & 0.00 & $(0.024)$ \\
\hline \multirow[t]{10}{*}{ A.S. Roma } & Net Profit & $(58,253,000)$ & $(40,130,000)$ & $(38,558,000)$ & $(41,166,000)$ & $(14,130,000)$ & $(38,447,400)$ \\
\hline & Current Assets & $78,524,000$ & $61,874,000$ & $93,064,000$ & $121,367,000$ & $112,100,000$ &, 800 \\
\hline & Liquid Assets & $24,709,000$ & $10,894,000$ & $9,108,000$ & $35,031,000$ & $8,700,000$ & $17,688,400$ \\
\hline & Fixed Assets & 636,000 & 521,000 & 481,000 & 862,000 & $1,500,000$ & 800,000 \\
\hline & Tangible Assets & $79,160,000$ & $62,395,000$ & $93,545,000$ & $122,229,000$ & $113,600,000$ & $94,185,800$ \\
\hline & Total Assets & $188,397,000$ & $173,966,000$ & $215,086,000$ & $298,580,000$ & $344,000,000$ & 05,800 \\
\hline & Current Liabilities & $142,046,000$ & $191,293,000$ & $188,487,000$ & $202,281,000$ & $234,800,000$ & 1,400 \\
\hline & Total Liabilities & $240,983,000$ & $240,132,000$ & $296,602,000$ & $401,003,000$ & $461,000,000$ & $327,944,000$ \\
\hline & Equity & $(52,586,000)$ & $(66,166,000)$ & $(81,516,000)$ & $(102,423,000)$ & $(117,000,000)$ & $(83,938,200)$ \\
\hline & Earnings Per Share & $(0.26)$ & $(0.18)$ & $(0.17)$ & $(0.10)$ & $(0.04)$ & \\
\hline \multirow[t]{10}{*}{ SS.. Lazio } & Net Profit & 580,492 & $(5,394,585)$ & $7,068,190$ & $5,812,193$ & $(12,625,154)$ & ,773) \\
\hline & Current Assets & $34,888,041$ & $32,844,789$ & $42,015,358$ & $43,087,955$ & $22,252,006$ & $35,017,630$ \\
\hline & Liquid Assets & $8,338,443$ & $5,938,190$ & $3,958,477$ & $2,940,539$ & $3,621,951$ & $4,959,520$ \\
\hline & Fixed Assets & $39,472,826$ & $38,730,949$ & $40,267,562$ & $41,462,466$ & $40,627,659$ & $40,112,292$ \\
\hline & Tangible Assets & $74,360,867$ & $71,575,738$ & $82,282,920$ & $84,550,421$ & $62,879,665$ & $75,129,922$ \\
\hline & Total Assets & $263,697,029$ & $232,545,620$ & $174,890,394$ & $177,369,842$ & $166,627,240$ & $203,026,025$ \\
\hline & Current Liabilities & $90,805,507$ & $74,872,109$ & $67,046,442$ & $68,569,687$ & $79,189,359$ & $76,096,621$ \\
\hline & Total Liabilities & $180,126,522$ & $154,422,159$ & $159,170,113$ & $155,825,442$ & $157,757,520$ & $161,460,351$ \\
\hline & Equity & $83,570,507$ & $78,123,461$ & $15,720,281$ & $21,544,400$ & $8,869,720$ & $41,565,674$ \\
\hline & Earnings Per Share & 0.01 & $(0.09)$ & 0.10 & 0.09 & $(0.19)$ & $(0.016)$ \\
\hline
\end{tabular}

Note. All figures in Euros. Sources: Investing.com (2016) and Morningstar (2016a, 2016b, 2016c, 2016d, 2016e, 2016f).

- $\quad T L / E, S T L / E, F A / E$ : As accounted for by these factors, Juventus and Lazio pose a possibility of financial hazard seeing as the cumulative equity ratios, those being TL/E, STL/E, and FA/E, are quite high. Such ratios suggest that Juventus' and Lazio’s equity capital may not be sufficient in meeting liabilities. Notwithstanding, Roma also appears to be in a precarious situation given the negative global equity ratios. 
- TA/TA: With respect to tangible asset capability, Lazio appears to manage this area best among the clubs, being the most flexible in this arena given the lower ratio. Roma and Juventus have similar TA/TA ratios.

- $N C / E$ : For each club, the NC/E ratio is equal to 1 , suggesting a balance between investments owned by shareholders and those retained by club management.

- EPS: Regarding share profits, each club has a negative EPS ratio, signaling that each club has been generally operating at a loss over the past five years.

- NP/TA: In terms of profitability from assets, Lazio ranks first, followed by Juventus. However, each club has a negative NP/TA ratio, signaling potential risks of loss stemming from its assets.

Table 3. Financial ratios of Serie A clubs

\begin{tabular}{lllll}
\hline Financial Indicator & Ratio & Juventus F.C. & A.S. Roma & S.S. Lazio \\
\hline Liquidity & CR & 0.37 & 0.49 & 0.46 \\
& LAR & 0.03 & 0.09 & 0.07 \\
Liability & NWC/TA & -0.39 & -0.40 & -0.20 \\
& TL/TA & 0.90 & 1.34 & 0.80 \\
TL/E & 8.53 & -3.91 & 3.88 \\
STL/E & 5.87 & -2.28 & 1.83 \\
FA/E & 3.17 & -0.01 & 0.97 \\
Profitability & TA/TA & 0.56 & 0.39 & 0.37 \\
& NC/E & 1.00 & 1.00 & 1.00 \\
& EPS & -0.02 & -0.15 & -0.02 \\
& NP/TA & -0.03 & -0.16 & -0.004 \\
\hline
\end{tabular}

Note. Ratios calculated using 5-year average data from 2011/12-2015/16 seasons.

\section{GREY RELATIONAL ANALYSIS (GRA)}

In order to analyze the ratio data, we conducted a grey relational analysis (GRA) to determine each club's performance with respect to their Serie A rivals. GRA is a multi-step procedure that provides a comprehensive ranking system for limited sets of data (Huang and Liao, 2003). According to Sakinç (2014), data are normalized, converted into grey relational coefficients, and subsequently ranked based on the resultant grades. To begin with, data are organized using a matrix system based upon specific metrics, in this case financial ratios. If larger values are desired, the benefit type factor calculations are required. However, if smaller outcomes are preferred, the defect type factor is utilized in computing coefficients. 
Following this, the grey relation degree is calculated by normalizing data using absolute differences between the referential series point (RF; denoted by the highest or lowest column value contingent upon the desired ratio outcome; $\mathrm{Wu}, 2002)$ and each data point within the matrix columns. Then, the difference scores are scaled by summing the matrix columns' minimal difference and maximum column difference. This value is then scaled through multiplication by a selected distinguishing coefficient (i.e., most commonly 0.5; Ecer and Boyukaslan, 2014; Sakinç, 2014). Subsequently, the difference scores and the calculated distinguishing column difference are divided by the scaled value. Finally, the relational degree is computed by summing each row indicators' coefficient scores and dividing by the proportion of the row factors and total row indicators. The process of the GRA calculation is displayed in Table 4.

Table 4. The GRA process

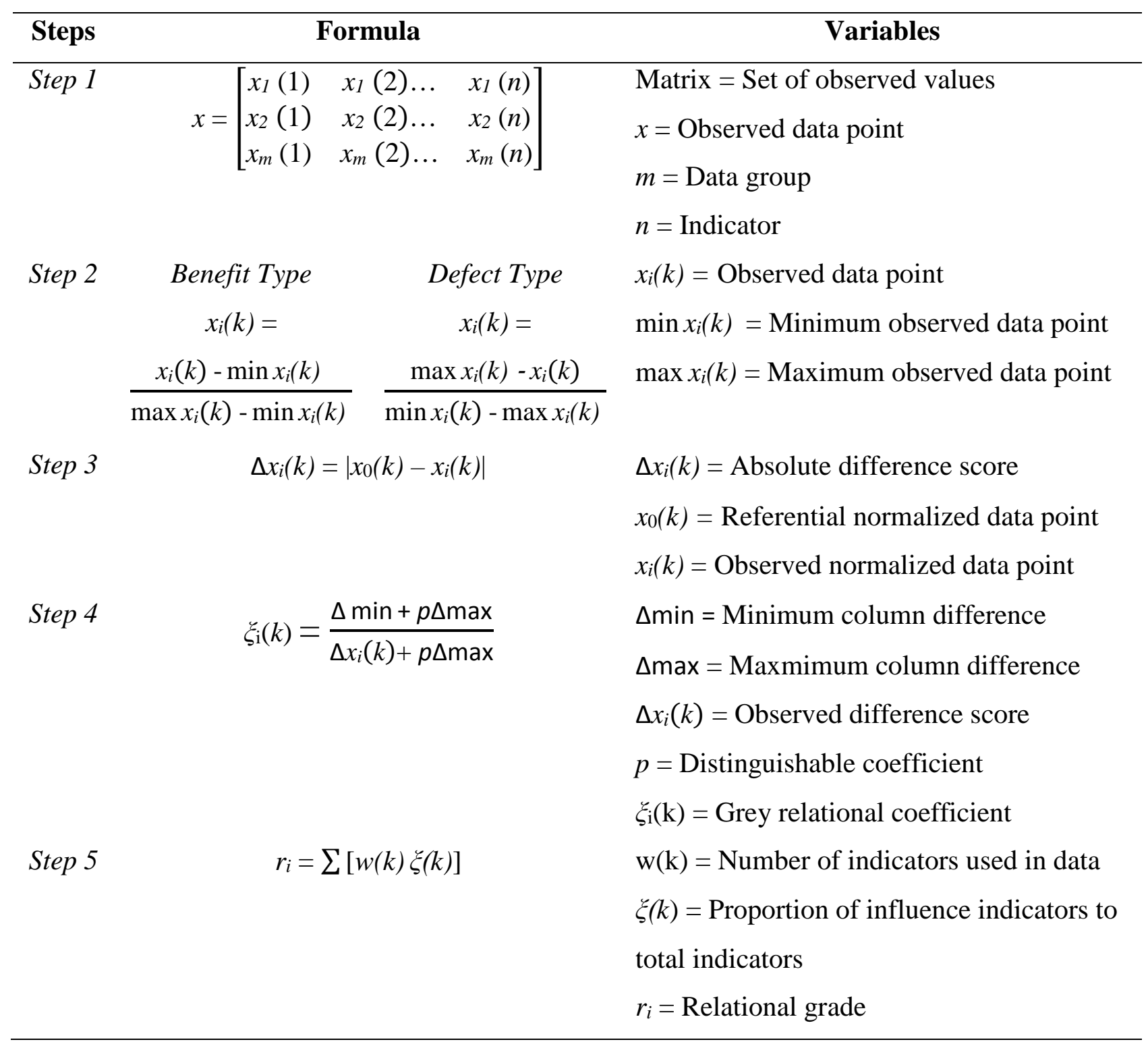

Note. Source: Sakinç (2014). 


\section{RESULTS}

\section{V.I. Performance Analysis}

In conducting the GRA, several considerations were made prior to performing the analysis. Since Roma reported negative equity in each of the five sampled seasons, we utilized the absolute value of this figure in the calculations of each corresponding ratio for the GRA. In addition, due to the NC/E ratio equaling 1 across the teams, we omitted this variable in our analyses as it was negligible for the purposes of the GRA. Lastly, given that the NWC/TA ratio was negative for each club, values closer to 1 were used as the RF value in the analysis.

The initial stage of the GRA involves arranging the comparison matrix composed of the financial ratios of each club, as displayed in Table 5. The RF value is derived from the set of ratio data. In the case of higher ratios signaling better performance, the RF value arises from the maximum value within the data set. However, if lower values are desired, the minimum value within the series of ratios is used as the RF indicator.

Table 5. Comparative ratios of selected Serie A clubs

\begin{tabular}{rccccccccccc}
\hline \multicolumn{1}{c}{ Liquidity } & \multicolumn{1}{c}{ Liability } & \multicolumn{4}{c}{ Profitability } \\
\hline & CR & LAR & NWC/TA & TL/TA & TL/E & STL/E & FA/E & TA/TA & EPS & NP/TA \\
\hline RF & 0.49 & 0.09 & -0.20 & 0.80 & 3.88 & 1.83 & 0.01 & 0.37 & -0.02 & -0.004 \\
JUVENTUS & 0.37 & 0.03 & -0.39 & 0.90 & 8.53 & 5.87 & 3.17 & 0.56 & -0.02 & -0.03 \\
ROMA & 0.49 & 0.09 & -0.40 & 1.34 & 3.91 & 2.28 & 0.01 & 0.39 & -0.15 & -0.16 \\
LAZIO & 0.46 & 0.07 & -0.20 & 0.80 & 3.88 & 1.83 & 0.97 & 0.37 & -0.02 & -0.004 \\
\hline
\end{tabular}

Subsequently, the next step of the GRA is normalization of the data based upon the RF values. In doing so, we employ either the higher (benefit type) or lower value (defect type) equation dependent on the desired ratio size. Table 6 presents our calculation of the normalized data matrix.

Table 6. Normalized ratios for selected Serie A clubs

\begin{tabular}{rccllccccccc}
\hline \multicolumn{4}{c}{ Liquidity } & \multicolumn{4}{c}{ Liability } & \multicolumn{4}{c}{ Profitability } \\
\hline & $C R$ & $L A R$ & $N W C / T A$ & $T L / T A$ & $T L / E$ & $S T L / E$ & $F A / E$ & $T A / T A$ & $E P S$ & $N P / T A$ \\
\hline JUVENTUS & 0.000 & 0.000 & 0.077 & 0.818 & 0.000 & 0.000 & 0.000 & 0.000 & 0.940 & 0.854 \\
ROMA & 1.000 & 1.000 & 0.000 & 0.000 & 0.995 & 0.888 & 1.000 & 0.917 & 0.000 & 0.000 \\
LAZIO & 0.769 & 0.539 & 1.000 & 1.000 & 1.000 & 1.000 & 0.698 & 1.000 & 1.000 & 1.000 \\
\hline
\end{tabular}

Next, the absolute differences of the normalized data are computed using the Step 3 equation displayed in Table 4. Absolute values are calculated by taking the absolute difference of each data point. In this case, a value of 1 is utilized, given the normalization of the data. Our normalized matrix is illustrated in Table 7. 
Table 7. Absolute differences of normalized data

\begin{tabular}{rllllllllll}
\hline \multicolumn{4}{c}{ Liquidity } & \multicolumn{4}{c}{ Liability } & \multicolumn{4}{c}{ Profitability } \\
\hline & CR & LAR & NWC/TA & TL/TA & TL/E & STL/E & FA/E & TA/TA & EPS & NP/TA \\
\hline JUVENTUS & 1.000 & 1.000 & 0.923 & 0.182 & 1.000 & 1.000 & 1.000 & 1.000 & 0.060 & 0.146 \\
ROMA & 0.000 & 0.000 & 1.000 & 1.000 & 0.005 & 0.112 & 0.000 & 0.083 & 1.000 & 1.000 \\
LAZIO & 0.231 & 0.461 & 0.000 & 0.000 & 0.000 & 0.000 & 0.302 & 0.000 & 0.000 & 0.000 \\
\hline
\end{tabular}

Following our absolute difference calculations, the grey relational coefficients are generated by employing the Step 4 equation from Table 4. Based on previous research (Ecer and Boyukaslan, 2014; Sakinç, 2014), we selected the value of 0.5 for $\xi$. Table 8 displays the calculation of the grey relational coefficients.

Table 8. Grey relational coefficients

\begin{tabular}{rcccccccccc}
\hline \multicolumn{4}{c}{ Liquidity } & \multicolumn{4}{c}{ Liability } & \multicolumn{4}{c}{ Profitability } \\
\hline & CR & LAR & NWC/TA & TL/TA & TL/E & STL/E & FA/E & TA/TA & EPS & NP/TA \\
\hline JUVENTUS & 0.333 & 0.333 & 0.351 & 0.733 & 0.333 & 0.333 & 0.333 & 0.333 & 0.893 & 0.774 \\
ROMA & 1.000 & 1.000 & 0.333 & 0.333 & 0.990 & 0.817 & 1.000 & 0.857 & 0.333 & 0.333 \\
LAZIO & 0.684 & 0.520 & 1.000 & 1.000 & 1.000 & 1.000 & 0.623 & 1.000 & 1.000 & 1.000 \\
\hline
\end{tabular}

Ultimately, in order to generate the comprehensive ranking of the GRA, we employ the Step 5 equation from Table 4. This calculation summates the grey relational coefficient and subsequently weighs each grade based on the proportion of the number of indicators utilized in determining each factor (i.e., the ratios used to indicate liquidity, liability, and profitability) by the singular ratio. The overall grade is similarly produced by summing all the ratios and then harmonizing the entire grade by the total number of indicators.

Table 9. Serie A grey relational coefficient assessment and club rankings

\begin{tabular}{rcccccccc}
\hline & $\begin{array}{c}\text { Liquidity } \\
\mathbf{( 6 4 . 5 2 \% )}\end{array}$ & $\begin{array}{c}\text { Liability } \\
\mathbf{( 6 8 . 7 3 \% )}\end{array}$ & $\begin{array}{c}\text { Profitability } \\
\mathbf{( 7 2 . 2 4 \% )}\end{array}$ & & Overall \\
\hline & Relation Grade & Rank & Relation Grade & Rank & Relation Grade & Rank & Relation Grade & Rank \\
\hline JUVENTUS & $33.33 \%$ & 3 & $40.30 \%$ & 3 & $83.37 \%$ & 2 & $47.52 \%$ & 3 \\
ROMA & $100.00 \%$ & 1 & $72.18 \%$ & 2 & $33.33 \%$ & 3 & $69.98 \%$ & 2 \\
LAZIO & $60.24 \%$ & 2 & $93.72 \%$ & 1 & $100.00 \%$ & 1 & $88.28 \%$ & 1 \\
\hline
\end{tabular}

\section{V.II. Results of GRA}

According to the global relation grades, as presented in Table 9, with a score of $72.24 \%$, profitability is the most potent indicator of financial performance for the measurement of Serie A football clubs that were examined in our study. Liability closely follows this with a score of 68.73\%, while liquidity is last with $64.52 \%$. In regards to liabilities, our results indicate that Lazio ranks first on liability (ri $=93.72 \%$ ) with Roma and Juventus respectively following with grades of $72.18 \%$ and 40.30\%. Our analyses also indicate that Lazio ranks first in profitability, with a relational grade of 
$100.00 \%$. Juventus trails slightly with a grade of $83.37 \%$, but Roma falls behind in this regard with a mere 33.33\% efficiency score on profitability. Taken together, the results of the GRA illustrate that Lazio (ri $=88.28 \%$ ) is the top ranked financial performer followed by Roma ( $\mathrm{ri}=69.98 \%$ ) as the second ranked and Juventus ( $\mathrm{ri}=47.52 \%$ ) as last among the sampled clubs.

\section{V.III. Supplementary Analyses}

Further analysis on the financial ratios using the negative equity for Roma as opposed to the absolute value (see Table 2) in the GRA marginally altered the final results. In terms of the ranking structure, Lazio remained as the top overall financial performer $(\mathrm{ri}=77.66 \%)$ followed by Roma (ri $=71.91 \%)$ and Juventus ( $\mathrm{ri}=47.52 \%)$ respectively. Using a paired-samples t-test to compare the original and further analyses, there was no significant difference in the relational grades, $\mathrm{t}(2)=0.74$, $\mathrm{p}=.54, \mathrm{~d}=0.43$. In addition, a Wilocoxon Signed-rank test indicated that the overall ranking structures did not significantly differ from each other $(\mathrm{z}=-.45, \mathrm{p}=.66)$. This was also verified by a perfect Spearman's rank-order correlation between the two ranking structures, rs(3) $=1.00, \mathrm{p}<.001$. Thus, the results from the original analyses were corroborated.

\section{DISCUSSION}

Taken as a whole, the GRA results rank S.S. Lazio as the holistically best financial performer over the past five years, followed by A.S. Roma and then Juventus F.C. In evaluating our findings, Roma ranks first in liquidity, as examined through current and liquid asset ratio values. In comparison to Juventus and Lazio, Roma appears to be much more capable of effectively managing their current and liquid assets than their competitors. Alternatively, however, another explanation for this disparity may be that Roma maintains a well-balanced debt/asset proportion and can more easily pay its shortterm debts while converting current assets to cash or liquid value. Another striking issue from our findings lies within Juventus' ineffectiveness in covering liabilities. Consequently, the club could potentially face massive financial difficulties in overcoming its short-term debts, as illustrated by the measures of liquidity (i.e., current and liquid assets). As a result, Juventus must treat asset management with great care in the short term.

Due to the lack of positive equity, it must be stressed that Roma's shares are quite risky due to their paltry asset structure and total asset value. Furthermore, over the past five years, there seems to be a growing trend of increased liabilities for both Roma and Juventus. While Lazio has been quite stable in this regard, they have not managed to bolster their total assets during this period. However, this may shed light on the club's ability to remain in accordance with UEFA's FFP regulations and thereby, avoid bankruptcy. Accordingly, compared to Lazio, Roma does not maintain a balanced debt 
to asset ratio, indicating that the club has relatively more liabilities than its assets. Nonetheless, Roma's liabilities include most of its debt as short-term liabilities, which they have been able to successfully regulate, as complemented by the ensuing liability relational grade.

Although Juventus has had a series of exceptional accomplishments during the past five seasons, the club has not been able to convert on-field success to their financial status. According to the findings, it seems that Juventus has selected a development model with higher assets and higher debt. Nevertheless, Juventus has translated this fiscal model into strong performance in profitability. This advantage may have sound implications for the club going forward, even though Juventus ranks last on the overall grade. Conversely, Roma falls short of profit distribution and reflects the worst earnings performance among the Serie A clubs, contrary to having better control over liability and greater liquidity than Juventus. As a result, Lazio appears to be rewarded by this balance in financial and on-field performance by taking first place in the overall ranking of the Serie A clubs included in our study through their effective management of liquidity, liability, and profitability.

\section{FUTURE DIRECTIONS FOR RESEARCH, LIMITATIONS, AND CONCLUSIONS}

From a global perspective, we can confidently state that football is the most attractive sport. In view of this, clubs face the issue of generating massive financial figures each and every day in order to compete with rival teams as well as the growing market. Nowadays, football clubs are eagerly looking for strong financial execution from management as well as outstanding performance from their players on the pitch. In reviewing prior cases throughout the history of football, many clubs have suffered financial difficulties as a result of not being able to use their sportive accomplishments as leverage to enhance their respective club’s economic infrastructures. Simply put, success is a twoway street given that football clubs are not only assessed with their on-field success, but also with the financial dealings with their stakeholders and their fans. This financial race and pressure for absolute success urges economic and sports analytics researchers to make more comprehensive analyses on this subject.

Within the extant literature in the financial analysis of football clubs, several MCDM methods can be used in measuring club financial performance, such as TOPSIS, VIKOR, Analytic Hierarchy Process (AHP) and so on (Opricovic and Tzeng, 2004; Yu, 2002). In covering the limitations of our study, naturally there exist a plethora of techniques that could have been applied as alternative procedures or perhaps even comparative or complementary analytic cases. In addition, although A.C. Milan, Inter Milan, alongside Juventus F.C. are known as the "Big Three” of the Serie A due to their respective unprecedented dominance in domestic play, we were limited by the use of Juventus, Lazio, 
and Roma as a result of these other clubs not floating on the Borsa Italiana. Thus, we were not able to present these clubs in our research.

However, we offer interesting directions for future studies as clubs such as these begin to trade publicly on the Borsa Italiana. In fact, with respect to future investigations, novel studies could concurrently examine not only each of the Serie A clubs, but also other "Big Five" league teams to uncover the world's most financially successful club. By utilizing financial accounts provided by publicly traded teams, future research could determine the type of financial structure that could benefit clubs the most in terms of liquidity, liability, and profitability. In doing so, sports scholars may be able to aid in the work of practitioners within the industry of football.

Taken together, financial performance is an extremely intricate issue in today's sports world. Although many clubs may seem to simply play to win, the ability to succeed is dependent on not only on-field performance, but also financial management. With this, we hope to inspire further studies of financial analysis in the realm of football to shed light upon the true states of international football clubs. Appropriately, the present study offers an application of financial analysis through the measurement of the economic conditions of floating Serie A football clubs using their financial tables from the 2011/12 to 2015/16 seasons. The GRA method has become a trending technique within the academic research world. Its appeal lies within its adaptability by means of rational and realistic outcomes using relation grades with limited data. Using the GRA method, we were able to classify the Serie A football clubs traded publicly on the Borsa Italiana.

Given that Lazio is ranked first by the GRA, we must consider these results along with success on the pitch, which has been dominated by Juventus. In other words, the competitive parity among the floating Serie A clubs may be closer than as indicated by our measures of financial performance. In delving further into this issue, we offer some evidence to ensure rationality in solving the abovementioned incongruences, while concertizing the internal consistency for our study. Consistent with this point of view, we can assume that possessing riskier financial structures, in the manner of Juventus, may deter the overall grade. Nevertheless, clubs like these provide opportunities for greater returns for investors in spite of the high risks. As a result, the clubs may be on more even playing field when taking into consideration liquidity, liability, as well as profitability. 


\section{REFERENCES}

A.S. Roma, 2016. History. [online] Available at: http://www.asroma.com/en/club/history.

Baroncelli, A. and Caruso, R., 2011. The organization and economics of Italian Serie A: A brief overall view. Rivista Di Diritto Ed Economia Dello Sport, 7(2), 67-85.

Baroncelli, A. and Lago, U., 2006. Italian football. Journal of Sports Economics, 7(1), 13-28.

Barros, C. P. and Rossi, G., 2014. A Bayesian stochastic frontier of Italian football, Applied Economics, 46(20), 2398-2407.

Barros, C. P. and Leach, S., 2006. Analyzing the performance of the English FA Premier League with an econometric frontier model. Journal of Sports Economics, 7(4), 391-407.

Berument, H., Ceylan, N. B. and Gozpinar, E., 2006. Performance of soccer on the stock market: Evidence from Turkey. The Social Science Journal, 43(4), 695-699.

Boeri, T. and Severgnini, B., 2014. The decline of professional football in Italy. In: Handbook on the Economics of Professional Football. Cheltenham, UK: Edward Elgar Publishing, pp. 322335.

Boidoa, C. and Fasanob, A., 2007. Football and mood in Italian stock exchange. Review of Financial Studies, 14, 1-27.

Deloitte, 2016. Revenue of the top European soccer leagues (Big Five*) from 2006/07 to 2016/17 (in billion euros). In Statista - The Statistics Portal. [online] Available at: https://www-statistacom.proxy.lib.umich.edu/statistics/261225/top-european-soccer-leagues-big-five-revenue/

Demir, E. and Danis, H., 2011. The effect of performance of soccer clubs on their stock prices: Evidence from Turkey. Emerging Markets Finance and Trade, 47(4), 58-70.

Ecer, F. and Boyukaslan, A., 2014. Measuring performances of football clubs using financial ratios: The grey relational analysis approach. American Journal of Economics, 4(1), 62-71.

Football Italia, 2014. Serie A table. [online] Available at: http://www.footballitalia.net/SerieA/season/2013-14/league-table.

Forbes, 2016. The business of soccer. [online] Available at: http://www.forbes.com/soccervaluations/list/\#tab:overall.

Franck, E. P., 2014. Financial Fair Play in European club football - What is it all about? University of Zurich, Department of Business Administration, UZH Business Working Paper, (328).

Gunardi, A., 2014. The implementation of UEFA Financial Fair Play: An analysis of financial performance of Manchester United. International Journal of Science and Research, 3(10), 612-620.

Günnemann, F., 2005. Sport stocks: Investment risk or opportunity? - Borussia Dortmund GmbH and Co. KGaA. 
Guzmán, I. and Morrow, S., 2007. Measuring efficiency and productivity in professional football teams: Evidence from the English Premier League. Central European Journal of Operations Research, 15(4), 309-328.

Hamil, S. and Walters, G., 2010. Financial performance in English professional football: 'An inconvenient truth'. Soccer and Society, 11(4), 354-372.

Huang, J. T. and Liao, Y. S., 2003. Application of grey relational analysis to machining parameter determination of wire electrical discharge machining. International Journal of Production Research, 41, 1244-1256.

Investing.com., 2016. Roma (ASR) - ASR Balance Sheet. [online] Available at: https://www.investing.com/equities/as-roma-spa-balance-sheet.

Investing.com., 2016. Roma (ASR) - ASR Income Statement. [online] Available at: https://www.investing.com/equities/as-roma-spa-income-statement.

Juventus Football Club S.p.A., 2016. Trophy room. [online] Available at: http://www.juventus.com/en/club/trophy-room/index.php.

Kiani Mavi, R., Kiani Mavi, N. and Kiani, L., 2012. Ranking football teams with AHP and TOPSIS methods. International Journal of Decision Sciences, Risk and Management, 4(1-2), 108-126.

Kuo, Y., Yang, T. and Huang, G. W., 2008. The use of grey relational analysis in solving multiple attribute decision-making problems. Computers and Industrial Engineering, 55(1), 80-93.

Montanari, F., Silvestri, G. and Gallo, E., 2008. Team performance between change and stability: the case of the Italian 'Serie A'. Journal of Sport Management, 22(6), 701-716.

Morningstar., 2016a. A.S. Roma SpA ASR - Balance Sheet. [online] Available at: http://financials.morningstar.com/balance-sheet/bs.html?t=ASRandregion=itaandculture=enUS.

Morningstar., 2016b. A.S. Roma SpA ASR - Income Statement. [online] Available at: http://financials.morningstar.com/income-statement/is.html?t=ASRandregion=ita.

Morningstar., 2016c. Juventus Football Club SpA 0H65 - Balance Sheet. [online] Available at: http://financials.morningstar.com/balancesheet/bs.html?t=0H65andregion=gbrandculture=en-US.

Morningstar., 2016d. Juventus Football Club SpA 0H65 - Income Statement. [online] Available at: http://financials.morningstar.com/income-statement/is.html?t=0H65andregion=gbr.

Morningstar., 2016e. Societa Sportiva Lazio SPA SSL - Balance Sheet. [online] Available at: http://financials.morningstar.com/balance-sheet/bs.html?t=SSLandregion=itaandculture=enUS. 
Morningstar., 2016f. Societa Sportiva Lazio SPA SSL - Income Statement. [online] Available at: http://financials.morningstar.com/incomestatement/is.html?t=SSLandregion=itaandculture=en-US.

Opricovic, S. and Tzeng, G. H., 2004. Compromise solution by MCDM methods: A comparative analysis of VIKOR and TOPSIS. European Journal of Operational Research, 156(2), 445455.

Pattnaik, M. and Bag, A., 2015. Fitting of logistic regression model for prediction of likelihood of India winning or losing in cricket match. In International Conference on Management and Information Systems September (Vol. 18, p. 20.

S.S. Lazio., 2016. History. [online] Available at: http://www.sslazio.it/en/club/history.

Sakinç, İ., 2014. Using grey relational analysis to determine the financial performance of Turkish football clubs. Journal of Economics Library, 1(1), 22-33.

Wu, H. H., 2002. A comparative study of using grey relational analysis in multiple attribute decision making problems. Quality Engineering, 15(2), 209-217.

Yu, C. S., 2002. A GP-AHP method for solving group decision-making fuzzy AHP problems. Computers and Operations Research, 29(14), 1969-2001.

Zuber, R. A., Yiu, P., Lamb, R. P. and Gandar, J. M., 2005. Investor-fans? An examination of the performance of publicly traded English Premier League teams. Applied Financial Economics, 15(5), 305-313. 